\title{
A reference ontology approach to support global product-service production
}

\author{
Claire Palmer, Esmond Neil Urwin, and Robert Ian Marr \\ Young*
}

Wolfson School of Mechanical and Manufacturing Engineering,

Loughborough University, UK

Email: c.palmer3@,1boro.ac.uk

Email: e.n.urwin@1boro.ac.uk

Email: r.i.young@1boro.ac.uk

*Corresponding author

\section{Eugenia Marilungo}

Università Politecnica delle Marche,

Ancona, Italy

Email: e.marilungo@pm.univpm.it

\begin{abstract}
The need to innovate and compete drives organisations to constantly seek new approaches to facilitate business and commerce. As market places become ever more globalised and digital economies grow, these organisations rely more heavily upon systems to design and deliver their products and services. Hence, when developing and operating a global production network the need for systems to interoperate between different domains and contexts within a global production network becomes paramount if organisations are to succeed. This paper puts forwards a reference ontology that has been developed to enable the interoperation of software tools involved in the global production of new product-services systems (PSS). It sets out the levels of the reference ontology, detailing closely the product-service aspects. This has been developed using a formal logic based approach. An example knowledge base has been created from industrial end user information with queries applied to this to provide a set of results showing the ability of the reference ontology.
\end{abstract}

Keywords: ontology, reference ontology, product-service system (PSS), global production network 


\section{Introduction}

To derive commercial and technological advantage in complex global markets requires companies to innovate and differentiate the way in which products and services are specified, designed and manufactured. One way to achieve this which has gained significant industrial interest is to move from a product-centred perspective to a more service-centred perspective, with many companies exploring how best to move from selling products to delivering product-service systems (PSS). The push towards servitisation (Vandermerwe and Rada, 1988; Goedkoop et al. 1999; Baines et al., 2007) and the selling of products via services is becoming ever more popular and more notably, profitable.

A full product-service system is aimed at fulfilling customer needs by selling the utilisation of a product i.e. the system, instead of providing just the physical product (Cook et al. 2006). It is also important to note that there are ranges of possible options that lie between a pure physical product and a full product-service system, where some levels of service are provided along with the purchase of a physical product. An example of this intermediate type of product-service is used in the experimental section of this paper.

Product-Service Lifecycle Management solutions have recently been helping the development of such PSS by improving the ability to organise, share and reuse information within and across organisations (Peruzzini et al., 2014). However, interoperability has long been recognised as fundamental to the ability to effectively share information between software tools ( $\mathrm{Li}$ et al, 2006) and similarly semantic interoperability, through the development of formal ontologies, has been recognised for many years as a key factor in achieving improved interoperability solutions (Gruber 1993).

Since Gruber's work a vast amount of ontology research has been undertaken across a wide range of target areas from very general purpose, or foundation ontologies, to very specific domain ontologies. There is a growing recognition of the need for ontologies that lie between these two extremes, sometimes called reference ontologies (Borgo 2007, Young et al 2009), to which this paper makes a contribution.

The aim of the FLEXINET project, from which this paper originates, is to create and develop a collaborative heterogeneous decision support environment to aid the design, configuration and reconfiguration of global production networks to meet new product ideas, including product-service 


\section{A reference ontology approach to support product-service production}

ideas. The FLEXINET research project has developed a reference ontology to support information sharing and thereby aid the decisions made within the early phases of PSS design.

The development of a reference ontology within the FLEXINET project has followed a qualitative approach. It has exploited the Noy and McGuiness (2001) knowledge engineering methodology together with Yin's (2013) case study methodology to guide the development of the reference ontology. The project has worked across three industrial sectors; white goods, industrial pumps, and food and drinks. They have provided an important source for derivation of user requirements and provision of industrial data and information for the research and offered different perspectives from which to develop and assess the research. While the reference ontology that has been developed covers a broad range, the significant elements from the point of view of product service systems and the production of such systems are the focus of this paper.

The paper is structured as follows. Section 2 provides a review of the relevant literature and how it reflects upon the FLEXINET approach. The FLEXINET reference ontology is described in section 3 with section 4 providing experimental results of the software implementation. These results are then discussed in section 5 and conclusions drawn in section 6 .

\section{Related work}

How to design a product-service system and setup the necessary support networks to facilitate its services is often complex and not always well understood (Gebauer et al., 2005; Baines et al., 2009; Spring and Arunjo, 2013). This can be attributed to a number of factors, the first being how best to integrate and accommodate the more common and accepted product lifecycles with the newer and progressive service lifecycles. The second is how to account for and overcome organisational, cultural, social and geographical differences between suppliers, producers and service providers within the context of a diverse and divergent Global Production System. Finally, the third factor underlying all of these issues is that of interoperability ( $\mathrm{Li}$ et al, 2006), it becomes paramount to be able to process and interpret information correctly and succinctly from all parties between potentially varied and diverse information systems and contexts to quickly and successfully design, implement and support PSS. The last of these three is the main focus of this paper. 


\subsection{Product Service Systems}

There are strategies and methods that currently exist that are designed to help organisations design for PSS and together with analysis of those strategies and methods (Spring and Arunjo (2013), Gaiardelli et al. (2014), Muto et al. (2015), and Vezzoli (2015)). Gaiardelli et al. (2014) set out a classification model for product service offerings. This consists of the main types and characteristics relating to product-service oriented services, use-oriented services, and results oriented services, (as put forward by Tucker (2004)) together with the product-oriented service space in an effort to unify and present a multi-dimensional model for the PSS domain. As such, this can be useful in helping organisations decide where PSS offerings can be aimed at for the market place. Spring and Arunjo (2013) put forward a model of service development in manufacturing focusing on the nature of connection between product and service. It is an interesting approach because it considers the ability to reconfigure networks and resources for the making of a product-service. This is an aspect that is potentially very useful on a global scale. Additionally, there is work published concerning partnership perspectives relating to the earlier stages of product-service system lifecycle management, but, as Lockett et al. (2010) point out that there is little study of supply networks for PSS, specifically the management and sharing of information between supply chain partners.

Considering the PSS domain there are a number of European Framework Programme 7 (FP7) projects that have produced research that contributes to it. In particular the POP* (Process, Organisation, Product and others) (Athena, 2006) methodology focused on the domain of enterprise collaboration and developing methods to capture design and management concerns within it. The Manufacturing Service EcoSystem (MSEE) project, focused upon service orientation and collaborative innovation for Virtual Factory Industrial Models (MSEE, 2014). This sought to model intangible and tangible assets relating to manufacturing activities using OWL based formal semantics. The FALCON project (Falcon, 2016) utilises machine translation and automated term extraction to construct a network of terms and translations inter-linked to each other and to source and target documents via URLs. Within the Product Domain the FP7 LinkedDesign Project has developed an integrated software platform (LEAP) to support designers, engineers and manufacturers throughout the product's lifecycle, from design, through installation and maintenance to disposal (LinkedDesign, 2014a). The platform contains tools capable of analysing information knowledge provided by different 
data sources present in the LinkedDesign application, such as dimensional quality control and product lifecycle costs.

\subsection{Interoperability and ontologies}

To deliver and develop effective Product Service Systems creates a need to generate, access, process and utilise information seamlessly and quickly between information systems. Thus, interoperability is of crucial importance if information generated by different systems is to be meaningfully applied to develop PSS. To achieve semantic interoperability enabling machine-understandable data to be shared by multiple organisations requires an ontological engineering process (Lee et al, 2009)

Recent ontological approaches within the product domain are those of Lee et al. (2009) and Panetto et al (2012). Lee et al (2009) suggest a 4layered product ontology architecture for an integrated value chain to achieve interoperability in the product domain. The architecture is based on the model driven architecture (MDA) with the two upper layers consisting of generic meta-models, the third layer being the domain ontology and the fourth layer the ontology instance. The ONTO-PDM ontology (Panetto et al, 2012) is based on the hypothesis that an ontological model of a product may be used to facilitate the interoperation of application software by enabling information sharing during the physical product lifecycle. ONTO-PDM consists of a common core model based on the standards ISO 10303 and IEC 62264. ONTO-PDM is based on First Order Logic and implemented by translation into OWL.

Considering the service domain, ManuHub (Cai et al, 2011) is a prototype Semantic Web system which enables the use of manufacturing services within distributed manufacturing environments. ManuHub achieves manufacturing interoperability by facilitating automatic retrieval of the required manufacturing services which are derived through a feature-based semantic matchmaking process. Structural knowledge is formalized using Ontology Web Language and constraint knowledge through the use of Semantic Web Rule Language (SWRL).

A formal representation of a PSS ontology is put forward by Annamalai et al. (2010). This was developed by way of a joint effort with multiple academic, industrial and governmental organisations contributing to its development. The ontology focuses on the constituent parts of a PSS ontology, those being: needs and requirements, stakeholders, business model perspectives, product-services, their associated lifecycle aspects and the resultant outcomes of a PSS. It is interesting in that it sets out view upon higher level domain concepts as constituent parts for an overall 
vision of what a PSS ontology is composed of. Wang et al. (2014) present a product-service ontology for manufacturing industry. This is composed of a modular approach used to build the product-service ontology together with a configuration method.

There are other interesting ontological research activities that whilst only focused upon one aspect, i.e. product or service, could potentially be enhanced if both products and services were focused upon to widen the ontologies. Borsato (2014) provides a perspective upon an ontology for product lifecycle management information relating to sustainable manufacturing. Dong et al. (2011) set out a feature based service product modelling ontological approach. The focus of this is services as products and the customisation of those services

A recent workshop for the MSEE project (Interoperability for Enterprises, Systems and Applications I-ESA 14 Workshop 9) has considered the use of standards to support interoperability for manufacturing servitization (Zelm and Chen, 2015) and represents the current state of the art in this domain. They state the need for further research to progress the application of ontologies to enable interoperability in the product service domain.

\subsection{Manufacturing Reference Ontologies}

An important route forward to enable interoperability across networks of enterprises and supply chains which function within different contexts is the development of manufacturing reference (core) ontologies. In 2006 Borgo and Leitao noted the lack of a formal ontology in the manufacturing domain. They go on to present an initial subset of a core ontology for the manufacturing domain which consists of an ontological classification of ADACOR (ADAptive holonic COntrol aRchitecture for distributed manufacturing systems) (Leitão et al., 2005) concepts according to the DOLCE foundational ontology.

Some examples of more recent developments are the work of LinkedDesign, and Kulvatunyou et al. LinkedDesign is a fundamental ontology designed to be easily adjusted and adopted for different product engineering systems (LinkedDesign, 2014b). The model consists of an upper ontology (about 30 concepts) and three specialized ontologies, one for each of the LinkedDesign FP7 project use cases. The specialization process has been performed in two steps: the first consists of a schema mapping approach; the second relates the fundamental ontology to a specific ontology through the use of a common concept (Milicic et al, 2012). 


\section{A reference ontology approach to support product-service production}

Kulvatunyou et al (2014) present a manufacturing service capability (MSC) model which utilises a reference-ontology-based semantic mediation approach using Web Ontology Language (OWL). The mediation approach creates logical mappings between specific supplier domain models and the reference ontology, forming a mapping chain across all the domain models. The International Federation of Automatic Control (IFAC) Technical Committee 5.3, Enterprise Integration and Networking puts forward a vision statement suggesting that a common core ontology is needed to support interoperability between different models within smart sensing enterprise systems (Weichhart et al, 2016).

Lee et al (2012) present a multi-level semantic product-modelling framework that can be applied to behaviour modelling whilst a reference PLM ontology is proposed by Bruno et al (2016) that includes concepts for design and manufacturing activities with the aim of creating, sharing, retrieving and preserving knowledge across the different stages of the lifecycle.

The Interoperable Manufacturing Knowledge Systems (IMKS) research project developed a formal ontological approach, based on Common Logic, to enable the sharing of manufacturing information and knowledge across multiple domains through the product life cycle phases. From this a set of core concepts were developed representing the design and manufacturing domains. It was shown that it was possible to specialise these core concepts to enable interoperability (Usman et al., 2013).

The work of the IMKS project was extended by two noteworthy research efforts. The first, that of Imran (2013) considered the extension of the approach into the domain of product assembly, whilst the second, by Hastilow (2013) extended the approach focusing on shop floor systems interoperability. Both of these further developed the set of IMKS core generic concepts for their respective domains to facilitate the creation of interoperable application specific ontologies.

The work that has been highlighted above points to research efforts focusing on the domains of Product Service Systems, interoperability, and formal reference ontologies. The work presented in this paper contributes to the on-going efforts to improve information and knowledge sharing through the progressive development of effective reference ontologies.

\section{The Reference Ontology focused on Product-Service Production}




\subsection{The Ontology Environment}

The premise of the FLEXINET reference ontology is to provide an ontological structure to support product design by way of 'what if' queries during the early stages of the product lifecycle. Across the full project this covers some 14 software tools, grouped in four areas of decision support: collaboration environments, business model development, risk assessment and network configuration. These are illustrated in figure 1, with the highlighted applications of idea manager, product-service configurator, existing supplier \& network knowledge and GPN configuration being the applications of relevance to this paper as they identify the requirements for product-service and production network representations.

Figure 1: The software tools developed in FLEXINET

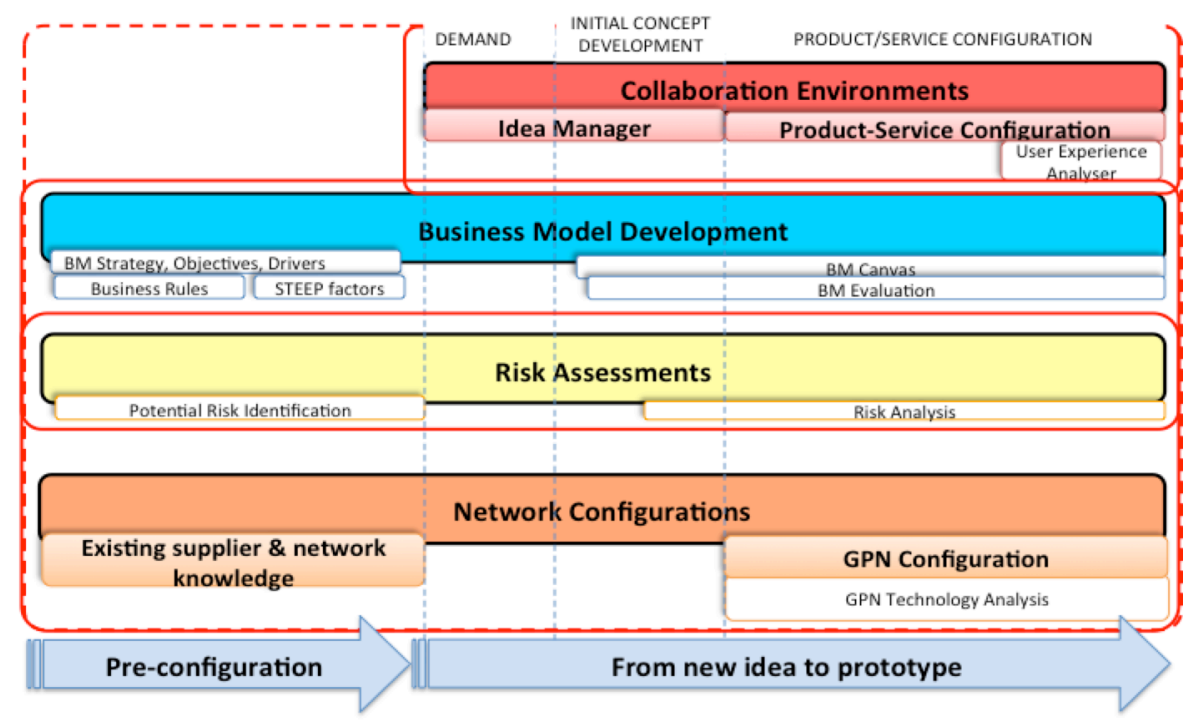

These software tools utilise and provide information results via the FLEXINET knowledge environment as illustrated in figure 2. The knowledge environment is built upon the reference ontology, but specialised as necessary to suit the needs of specific end user companies. The resulting company knowledge base can then be queried by any application for information or it can be updated by each application. For example new suppliers of physical products or service support can be added to the $\mathrm{KB}$ and then evaluated during network configuration against the needs of the new product-service under development. 
Figure 2: The FLEXINET knowledge environment

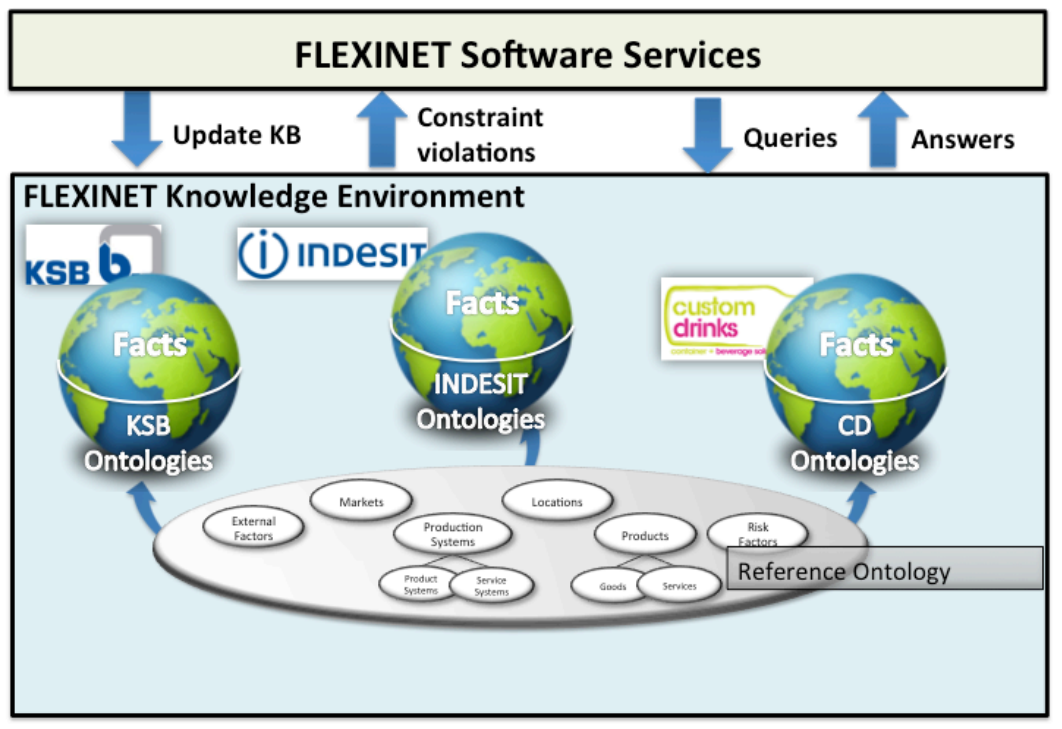

\subsection{The Ontology Overview}

FLEXINET takes the view that to be effective across multiple domains and extensible in the future it is important that a reference ontology is progressively specialised from generic concepts to the specific concepts needed in each domain area. The FLEXINET reference ontology is specialised through four specific levels as set out in Palmer et al. (2016) ranging from level 1 to level 4, but utilising a generic upper level ontology above this, at what has been called level 0 . In the case of FLEXINET this level 0 ontology is provided by HIGHFLEET's Upper Level Ontology (ULO) (Highfleet, 2014). Each subsequent level is then further specialised adding more meaning and context.

Level 1 represents the key concepts relationships and constraints that apply within a generic systems context. Level 2 extends these concepts to include all relevant concepts that may be relevant to any designed systems 
Level 3 provides the context for further specialisation at level 4; in our case manufacturing business systems. Level 4 then focuses the ontology specifically upon product lifecycle systems. This can then be mapped to specific business needs at level 5. A general view of these and the context for each level is illustrated in figure 3. Please refer to Palmer et al. (2016) for more detail about the reference ontology levels.

Figure 3: FLEXINET ontology specialisation levels

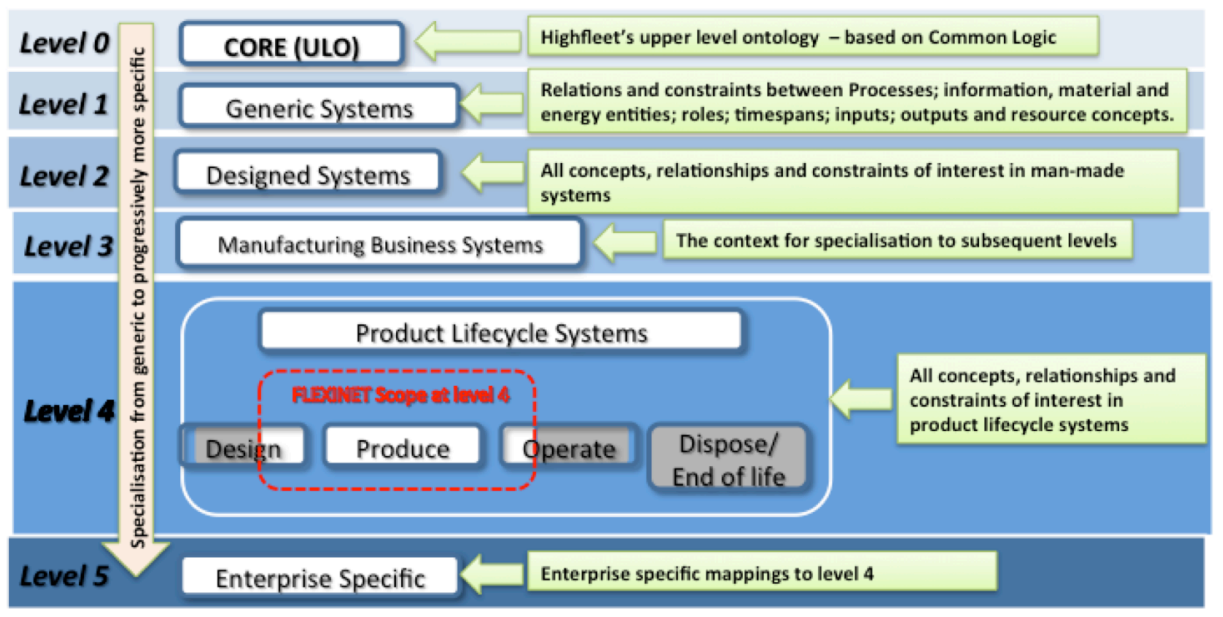

The domains of concepts needed to support the full range of functionality of FLEXINET applications are illustrated in Figure 4. This presents the broad range that needs to be covered to meet the requirements of business model development and new product development.. "Product" represents the development of product-services and relates to "production network" which is a specialisation of the "network" concept shown in figure 4. "Production network" represents suppliers within a globally dispersed area that can produce a manufactured product. Network, then relates to "location", "scenario", business and "risk". Scenario provides a way of representing alternative possible solutions, where each scenario represents a potential solution that can be used to undertake 'what-if' analysis. "Metrics" represents properties that can be used for measurement. "Indicators" are properties that can influence decisions. These can, for example in a global regional context, be political, human resource and environmental factors. "Location" is used to determine a particular place or region.

To support interoperability three types of relationship exists between the domains of the reference ontology as illustrated in figure 4; 
direct relationships, containment relationships and indirect relationships. Direct relationships are defined when properties (ontological classes) situated in two or more domains are linked directly in a cross-domain relation. A containment relation is a specialised form of a binary direct relationship. It occurs when a property in a domain forms a container for a component property in a separate domain. Indirect relationships are comprised of two or more relations connecting separate domain areas within the reference ontology. They are formed from a chain of arguments which act as connectors between the relations, i.e. Argument A (domain $\mathrm{X}$ ) is associated with argument $\mathrm{B}$ (domain $\mathrm{X}$ ) via relation 1. Argument $\mathrm{B}$ is associated with argument $\mathrm{C}$ (domain $\mathrm{Y}$ ) via relation 2 .

The research that is presented in this paper is the creation and formalisation in first order logic of an ontology to support the design and development of product-services and the subsequent impacts this might have upon a global production network. Hence, the focus within this paper is upon the product and production network aspects as represented within Figure 4. The premise behind this is to support organisations as they design and configure product-services so as to be able to introduce and take advantage of new technological innovations for both the product and service aspects involved. The aim is to support the decision making process during the specification and design phases of product-service development.

Figure 4: Areas of ontology development in the Reference Ontology

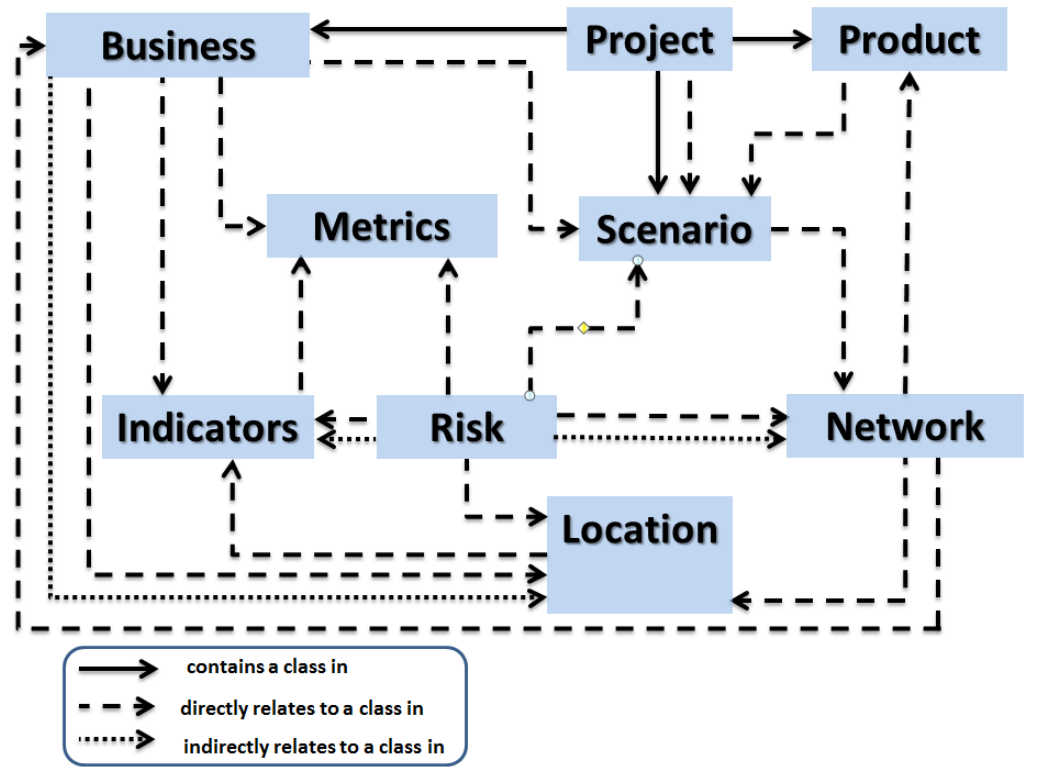


The FLEXINET reference ontology that has been built to support products and product-services is now explained in the following section. Firstly, the level 2 product model is explained, this is then followed by a description of the level 4 manufactured product model. For each of these models the relationships and constraints are detailed to fully explain the approach to modelling and representation within the ontology.

\subsection{The Product Concept, its relationships and constraints}

To visually represent the FLEXINET reference ontology the Unified Modelling Language (UML) has been used to model the concepts and relations that describe 'Product' at level 2 as presented in Figure 5. This UML model is intended to highlight the main aspects of the reference ontology that relate to 'Product', as such it is a small part of the FLEXINET reference ontology. The parent concept for the product model is 'Product', as such this is specified as 'a product is a process output', this is a type of 'Role', which, is specified at level 1 of the reference ontology and therefore inherits from this concept. The concepts of 'Physical Product' and 'Service Product' are types of 'Product' at level 2. 'Physical Product' represents 'material artefacts, e.g. cars, boats, planes', while 'Service Product' that is an 'Actor' role (thus inheriting from it) represents 'an offering, e.g. maintenance, repair, insurance'. In turn, 'Physical Product' can have a 'Prototype', the cardinality of zero to many states that this is optional, this inherits from 'Material' at level 1. 'Product Service' is a type of 'Physical Product' to which this is composed of at least one 'Service Product', a definition of this is 'an integrated product and service offering that delivers value in use'. 'Service Using Product' is composed of at least one 'Physical Product', and is denoted as 'an offering that employs a product'. 


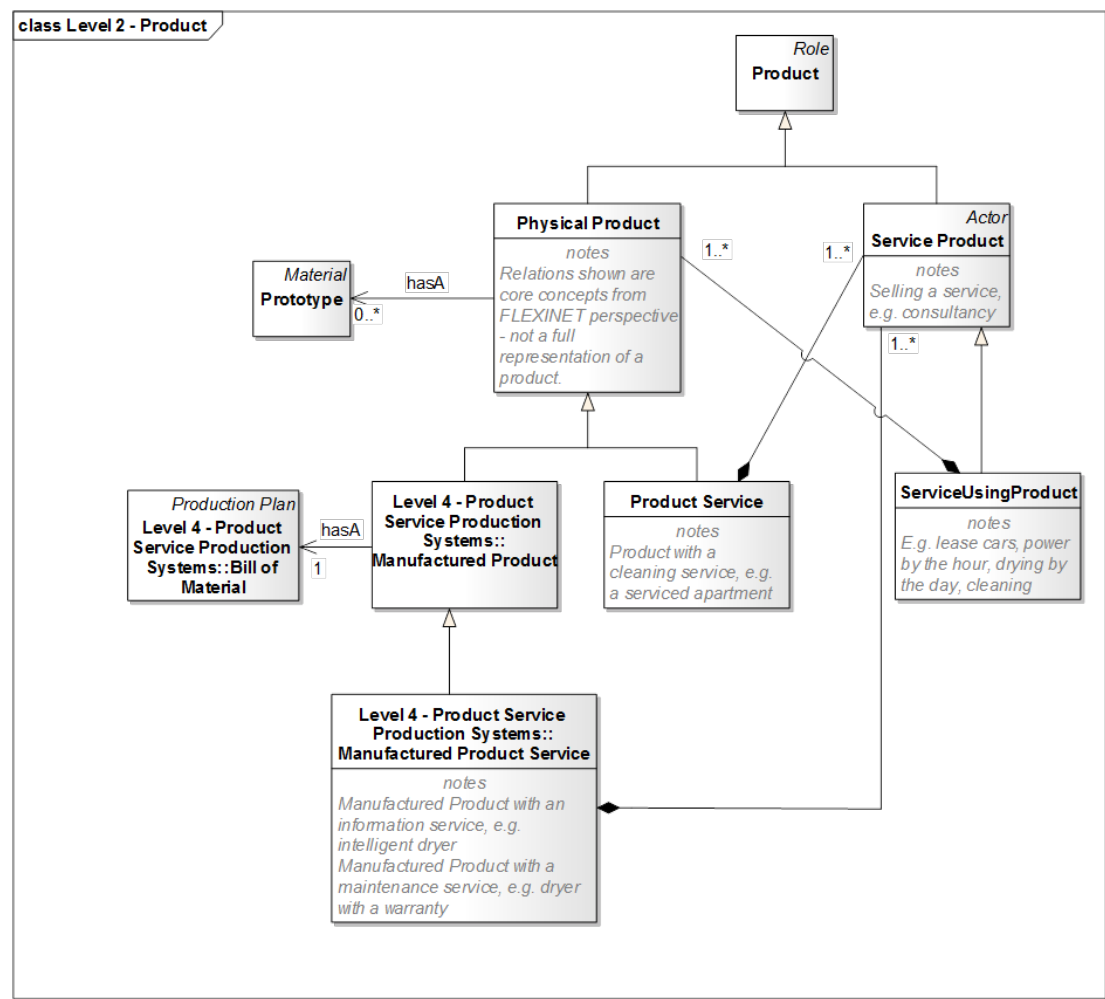

The 'Product' UML model illustrates 'Product' and how it has been modelled within the FLEXINET project. It enables the representation of not only a traditional 'Physical Product', but, 'Service Product', 'Product Service' and 'Services Using Product'. Here product is assumed to be anything that is sold or saleable, whether physical or not. A "Physical Product" is clearly a physical entity that is saleable e.g. a washing machine. A "Service Product" is a pure service that can sold which may or may not involve physical devices e.g. consultancy services. A "Service using a Product" represents what is most typically considered to be a product service system e.g. "power by the hour". However a 
"Product Service" in this model represents a physical product that also provides services e.g. a machine that automatically provides useful information to support the user, such as when it is most economic to use it or when it may require a maintenance service.

This structure of relationships enables a clear link to manufacturing requirements where all "Physical Products" will be manufactured with some necessary bill of materials, while manufactured products with a service (Manufactured Product Service) will have a link to the service that is provided (Service Product). These distinctions are necessary when employing the FLEXINET reference ontology for businesses that supply physical products while considering the move towards product servitisation.

The FLEXINET reference ontology is being built by employing a first order logic heavyweight computable approach. The Knowledge Framework Language (KFL) (Highfleet 2014), is a Common Logic (ISO 24707) based language is being used to develop the reference ontology. This is comprised of properties (concepts), relationships, constraints and rules. The following text sets out some examples of the KFL code that illustrates key types of representation used in the reference ontology.

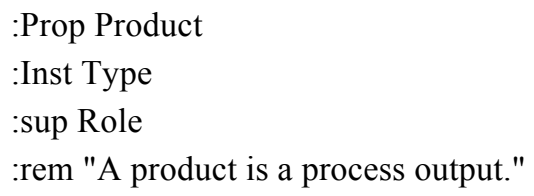

The statements above states that 'Product' is a KFL property ("prop"), that is equivalent to a class in UML and maps to the UML model in Figure 5. It states: that Product is an instance of a type (Inst Type) where type comes from the ULO and defines something that always exists; that Product is a specialisation of Role (sup Role) which is a property defined at level 1 and identifies that a product is an entity that will play a role in some system.

The statements below illustrates the KFL to capture the relationship that a ProductService must contain at least one service.

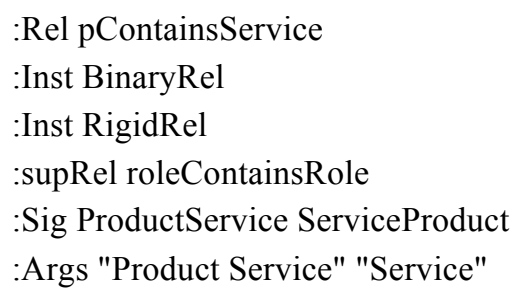


A reference ontology approach to support product-service production

:lex "Product Service ?1 contains a Service ?2"

:rem "A ProductService contains at least one Service."

While the KFL above represents the content of the UML class diagram, axioms can also be added, such as that illustrated below which specifies that if a service exists then it is provided by a system and that system will require an input to function.

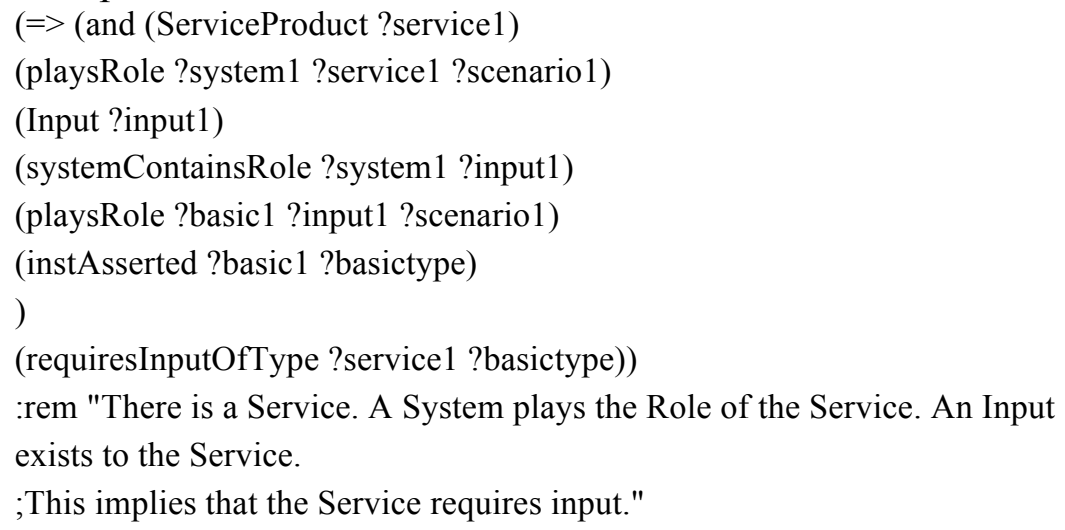

A range of product related axioms have been identified and implemented a number of which are listed below:

1. Axiom - A ManufacturedProductService should always associated to a Benefit.

2. Axiom - A Concept should always be associated to at least one Idea.

3. Axiom - If there is a ManufacturedProductService, then it has an associated Life Cycle.

4. Axiom - If there is a Concept, then there will be an associated Product.

5. Axiom - If there a Support System, then there is a ManufacturedProductService that uses it.

\subsection{The manufactured product and its production network}

The Bill of Material, as illustrated in figure 5 provides the important link from the product under development to the production network that is needed to produce and assemble the component parts or services that it requires. Networks in FLEXINET have been defined in relation to scenarios, as this supports multiple alternative instances that can be evaluated to identify the preferred network solution. The representation is illustrated in figure 6 and shows how a network scenario 
is a model of flows between systems with inputs and outputs and that can capture the typical alternative flow relations of process flow models where alternative types of gateway can be employed to represent alternative possible flow options. Importantly the outputs from specific production systems represent the components in the bill of materials. In combination these should result in the production of the required product or service.

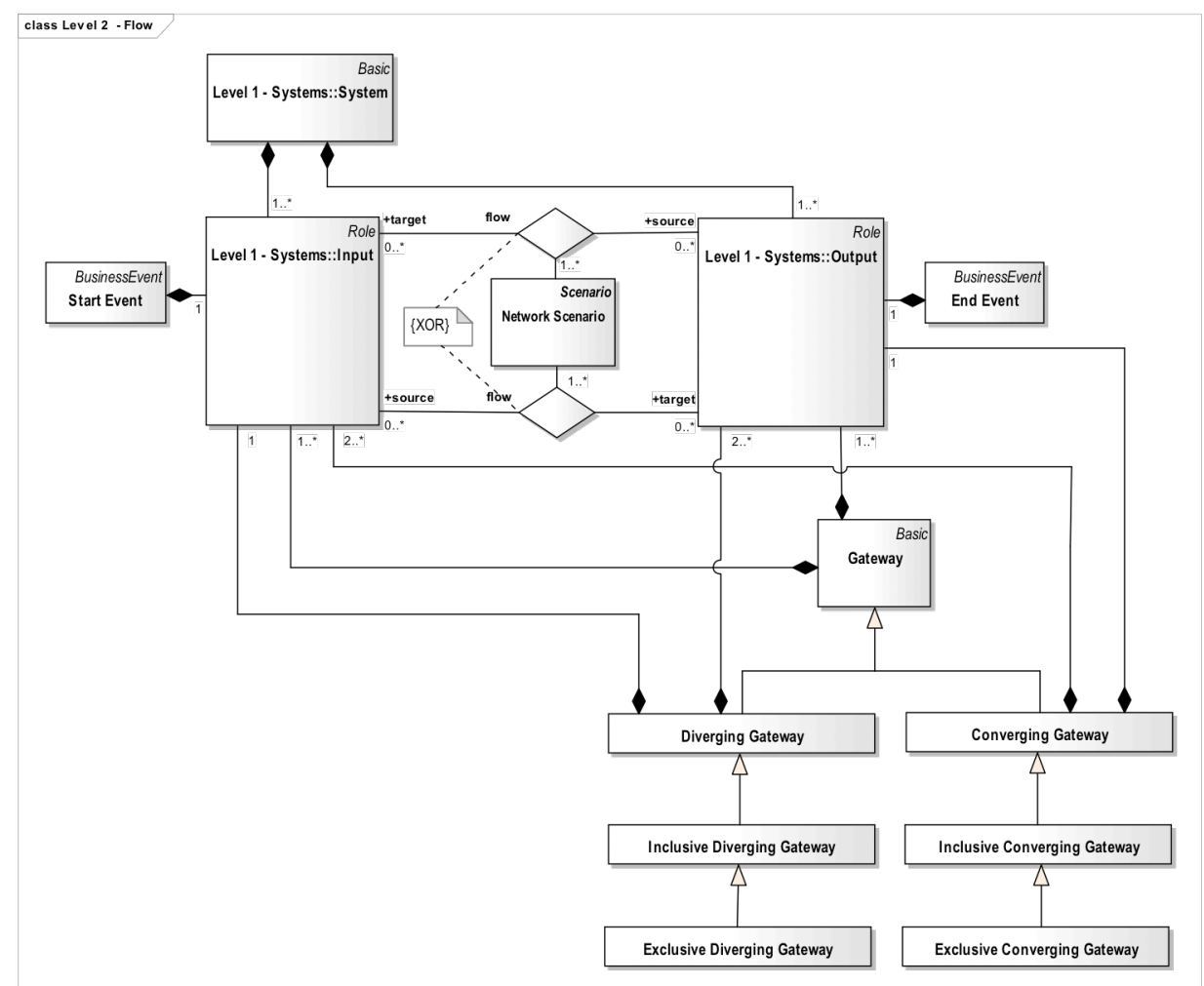

Figure 6: The UML Class diagram describing networks

Again these concepts and relations have been modelled in KFL. A slection of Important axioms that have also been modelled are:

1. Axiom - A flow can only exist between an Input and an Output or an Output and an Input.

2. Axiom - A flow can only exist from a target to a source or a source to a target but not in both directions (XOR).

3. Axiom - In a flow relation the source basic must flow to target. 


\section{A reference ontology approach to support product-service production}

4. Axiom - A network scenario should contain more than one system.

5. Axiom - A gateway must have one input and one output.

6. Axiom - A diverging gateway has only one input and 2 or more outputs (describes an opening AND or a fork.

7. Axiom - A converging gateway has 2 or more inputs and only one output (describes a closing AND or a join.

8. Axiom - An inclusive diverging gateway (opening OR) has one input and 2 or more outputs An output must have a condition (a Boolean).

9. Axiom - An inclusive converging gateway ("closing OR") has one default output and two or more inputs. An input must have a condition (a Boolean).

10. Axiom - An exclusive diverging gateway ("opening XOR", branch) inherits from an inclusive diverging gateway.

This representation enables production networks to be configured to meet a specific product demand, given that potential global suppliers of products or services can be identified.

\section{An experimental evaluation}

The industrial case study inside the FLEXINET project and used by this paper involves a company producing household appliances, and having a worldwide network made up of numerous suppliers and commercial branches distributed all over the world. As such the company is interested in innovating its actual business through services (i.e. it moves from a product focus to product-service) and delivering a new product-service solution, namely Energy Saving Dryers. The main challenge is designing a product-service able to reach the customers' needs and identifying the right business model able to satisfy their expectations. According to this aim, the product is a dryer embedded with additional sensors and components. The services to be provided are an energy awareness service and a smart maintenance service. The energy awareness service will enable the product energy consumption to be controlled and optimised and make the user aware about the energy consumed by each cycle and during the day/week/year. The energy awareness service will enable best practices to be deduced, thus providing the user with advice as how to improve the efficiency of the machine.

The smart maintenance service will monitor the current state of the machine, thus enabling efficient management of the maintenance process 
by partners involved (i.e. the user, department and external technical partners). This monitoring also enable dangerous situations to be detected and this information to be made available via internet and mobile phone and technical assistance actions activated.

Figure 7 Awhite goods Drier product-service

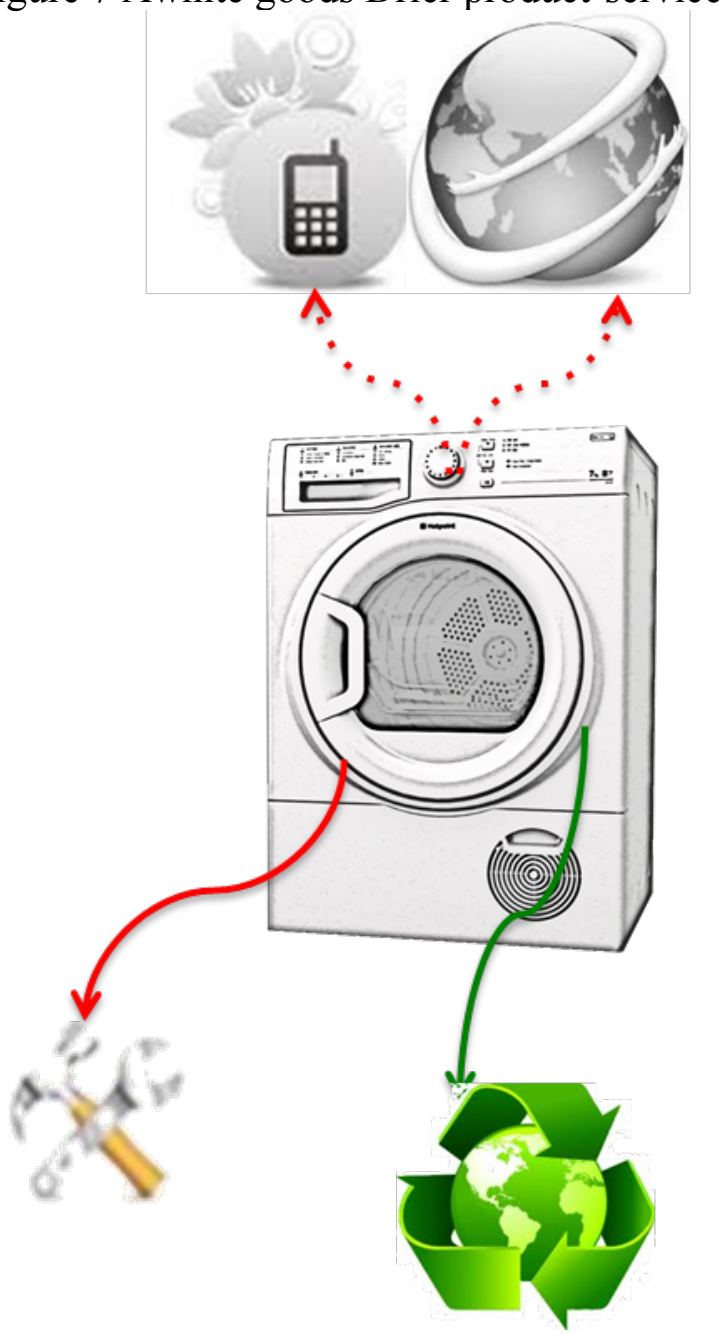

To encompass the aims of the product-service the product needs the ability to communicate live information electronically with the White Goods company. This paper will consider the product-service 'i_Dryer001' and focus on the smart maintenance service

. Each of the dryer's components is associated to one or more suppliers able to provide that component and placed in a specific location in Europe or around the world. Each supplier was modelled in terms of facility, industrial process and semi-finished good in output. All the 
outputs provided by these suppliers are used as inputs in the main company industrial process to generate the smart maintenance productservice.

The example in Table 1 shows thirteen components which can be supplied by three different suppliers from Singapore. Each of these components is then assembled into the final product at producer England1.

Table 1 Instances in the knowledge base

\begin{tabular}{|l|l|}
\hline \multicolumn{1}{|c|}{ Property } & \multicolumn{1}{c|}{ Instances } \\
\hline $\begin{array}{l}\text { Manufactured Product } \\
\text { Service }\end{array}$ & i_Dryer001 \\
\hline Service & Smart Maintenance \\
\hline Component & $\begin{array}{l}\text { Controls Module Set, Main Controls, U board, } \\
\text { U bracket, I board, I housing, and RFI filter, } \\
\text { Harness, RFI filter, Harness channel, } \\
\text { Connectivity, Antenna, External Coordination } \\
\text { Module }\end{array}$ \\
\hline Producer & England1 \\
\hline Suppliers & Singapore1, Singapore1-2, Singapore1-3, \\
\hline
\end{tabular}

The idea manager and product service configurator applications support the users in defining the product and specifying the necessary components. These are input to the knowledge base. The Existing Supplier application will also populate the KB with information about suppliers that are known to the business. The Production Network Configurator application then enables a new GPN to be defined by selecting the appropriate suppliers for each of the components identified in the Bill of Materials. An illustration of global suppliers in the GPN configuration application is illustrated in figure 8 . 
Figure 8 Globally dispersed suppliers in the knowledge base

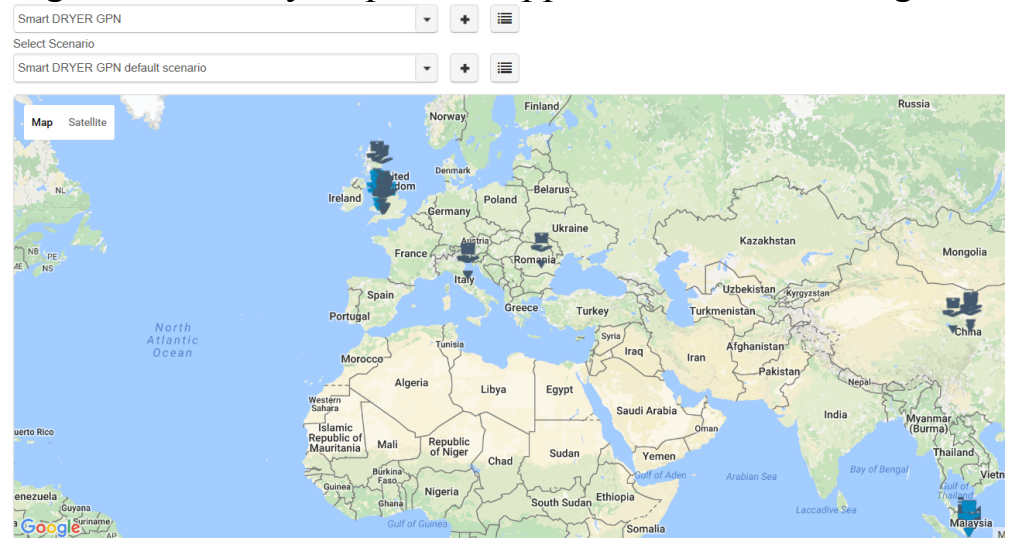

Information is input to the $\mathrm{KB}$ through direct interfaces with the $\mathrm{KB}$, while the KB can be interrogated by applications via sets of queries.

Typical product related queries are:

Product Query 1. List all the Product-Services.

Product Query 2. What are the Product-Services associated to an Idea?

Product Query 3. What are the keywords associated to an Idea?

Product Query 4. What are the Product-Services related to a given keywords?

Product Query 5. What are the Support-Systems that a Product-Service uses?

Product Query 6. What are the Product-Services associated to a Concept?

Product Query 7. What Benefit is associated to a Product-Service?

Product Query 8. What are the Product-Services associated to a Requirement?

Product Query 9. What Requirements and Stakeholders are related to a Product-

Service?

Product Query 10. List the Software and Hardware components of the Infrastructure that are used by the Support-system of a Product-service.

Product Query 11. What is the Life-Cycle associated to the Product-Service?

Product Query 12. Which components do the Product i_Dryer001 and the Service SmartMaintenance both utilise in Global Production Network Scenario PSP_GPN?

Product Query 13. Does the product i_Dryer001 contain the component Uboard which is required by Service SmartMaintenance? 
A reference ontology approach to support product-service production

Product Query 14. Which components does the Service SmartMaintenance require which are not contained by the Product i_Dryer001?

An illustration of the full query 123 above along with its results is provided here:

Figure 9: Product-Service Query 13 and its results

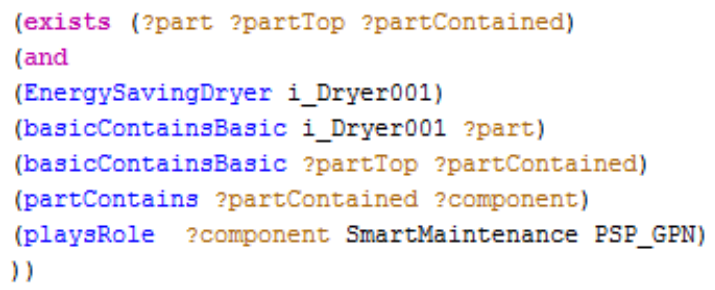

\begin{tabular}{l}
\hline ?component \\
\hline Harness \\
\hline Iboard \\
\hline Ihousing \\
\hline RFIfilter \\
\hline Uboard \\
\hline Ubracket
\end{tabular}

Similarly queries have been produced to support the development of a global production network such as:

GPN Query 1. List the Facilities for a given organisation.

GPN Query 2. Where are the facilities of an organisation located?

GPN Query 3. List the suppliers by Region or Country.

GPN Query 4. List the connectivity between pairs of systems within a network.

GPN Query 5. Given a new product with a list of requirements associated with them, which is the GPN configuration able to produce the new product?

GPN Query 6. Given a new product with a required technology, which are the suppliers that can provide this technology? 
GPN Query 7. Given a new product with a specific need for a technology, which are the systems of the current configuration of the GPN able to produce the product?

GPN Query 8. List the GPN suppliers that can provide motor components.

GPN Query 9. List the GPN suppliers that can provide electronic equipment.

GPN Query 10. Which suppliers in Global Production Network Scenario PSP_GPN supply the component Uboard as an output?

GPN Query 11. List the kinds of assets that the GPN suppliers can provide.

GPN Query 12. List of technologies by Product.

GPN Query 13. List of Experts by technology and where they are located.

GPN Query 14. Do we have experts in a technology? If so, where are they located?

GPN Query 15. List the kinds of assets that the GPN suppliers can provide.

An illustration of query 10, identifying the potential suppliers for the Uboard component in the product is shown in figure 10. This takes as input the component, already input to the $\mathrm{KB}$ via the Product-Service Configuration application and then outputs the potential suppliers. This type of query is used in the GPN configuration application, but with the Uboard component identified by the user via the application.

Figure 10: GPN Query 10 and its results

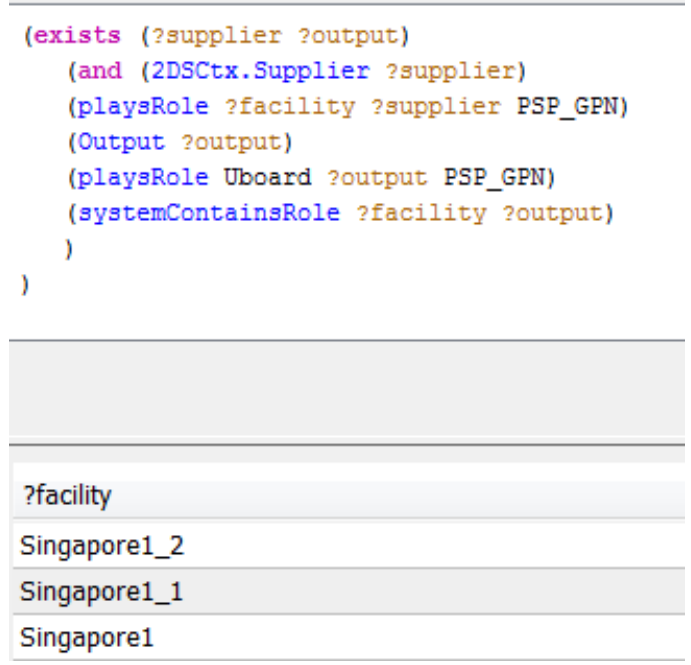

The approach provided by the FLEXINET reference ontology allows a potentially wide variety of software applications to interrogate the 
knowledge base to add information into it. In this case especially the Idea manager, the Product-Service Configuration Application, the supplier Knowledge Application and the Product Network Configuration Application, as described in section 3.1

\section{Discussion}

What has been found during the development of a reference ontology to support global production systems is that, whilst there are examples of ontologies for the Product-Service domain, few exist that apply to the domains of manufacturing. Additionally, little has been found relating to the development and application of a reference ontology for this domain either.

The FLEXINET project has set out to develop a reference ontology to foster and promote interoperability involving three industrial end users from three quite different contexts. This bottom up approach has enabled these perspectives to enrich and help validate the reference ontology. Furthermore, the search for and application of international standards has helped the reference ontology by influencing its development from a top down approach. Focusing on standards such as the Process Specification Language (ISO, 2004) has helped align the higher level generic properties within it to conform where applicable to those standards and thereby strengthen its interoperation objective. These approaches have been helped by iterative development processes brought about by a set of end user requirements, uses cases and scenarios together with feedback loops brought about by the testing and deployment of the FLEXINET services utilising the end user and references ontologies.

The heavyweight first order logic approach brought about by the reference ontology for the domain of GPN has, enabled it to be more semantically expressive than an approach utilising OWL (Palmer, et al. 2016). Additionally, the product-service ontology presented herein, goes some way to providing a manner in which products and services can assess and devise new ways in which to design and reconfigure those product-service systems. This, together with the ability query a GPN and the suppliers within a knowledge base to provide options for potentially different configurations of suppliers thereby, potentially influencing cost, quality and time could be of real benefit to those end users. Hence, the product-service production ontology, developed upon the ideals of interoperability, presents a feasible approach to providing decision support to the process of product-service provision for GPN. 


\section{Conclusions}

The ability to combine, create, configure and reconfigure both products and services in an efficient, effective and innovative manner can help businesses compete in a global market place and then derive benefit from it. The FLEXINET project has developed a set of software application and services to provide end users with decision support tools under pinned by the reference ontology to help develop products and services utilising a supporting GPN.

The product-service ontology set out within this paper has sought to demonstrate a reference ontology that can support product-service development for Global Production Networks. This has been developed in a semantically rigorous heavyweight approach utilising first order logic. Two research questions were set out in the methodology section of this paper they were (i) 'can a heavyweight first order logic reference ontology structure be developed to define and represent product, service and product-service knowledge for GPN?' and (ii) 'can this ontological structure then be populated and queried to enable the design, configuration and reconfiguration of products, services and product-services for GPN?'. The paper has set out an ontological product model both at level 2 and level 4 of the reference ontology to fulfil and answer this question. These information structures have been able to represent products and services for three different end user domains within the project. Therefore, they can be put forward to help organisations build and produce interoperable information systems to support 'what-if' questions posed when considering multiple combinations of products and services. With regard to the second question, the results section of the paper has endeavoured to show that a knowledge base has been created and populated (instantiated) using industrial end user information. This has then been applied to a number of end user queries to elicit responses to show that products and services can be assessed for design and reconfiguration. Moreover, the knowledge base has then been queried to show that there are a number of different potential suppliers within the GPN that could be used to change and configure an existing GPN. Hence, the ontology has been able to provide positive answers to both research questions.

Reflecting upon the ability of the ontology to apply to and represent a multitude of other domains is something that raises questions. The scope of the FLEXINET project has restricted the reference ontology the domains of manufacturing and GPN. Hence, there is potential to produce further work and extend the scope of the reference ontology to look at different domains and other parts of the product-service lifecycle. This could include manufacturing processes, the assembly of product- 
services and operation within their intended environment. Final testing of the FLEXINET applications, services and ontologies is currently being conducted by the industrial end users, this will provide invaluable feedback as to the ability of the reference ontology to represent their domains and effectively support queries about product-service development for GPN. This will then help the reference ontology to be further enhanced by bringing clarity and precision to its semantic representation of the GPN domain.

\section{Acknowledgements}

The research leading to these results has received funding from the European Commission's 7th Framework Programme under grant agreement no NMP2-SL-2013-608627.

\section{References}

Annamalai, G., Hussain, R., Cakkol, M., Roy, R., Evans, S., and Tiwari, A. (2011) 'An ontology for Product-Service Systems', Decision Engineering Report Series, Eds., Rajkumar Roy and Yuchun Xu. Cranfield University

Athena, 'Advanced Technologies for Interoperability of Heterogeneous Enterprise Networks and their Application', FP7 no 507849, 2006, POP* Revised Framework - Work Package A1.8. Amerigo, Supply Chain Mapping, Program Profit - IBB 2007, Zwischenberciht.

Baines, T.S., Lightfoot, H., Steve, E., Neely, A., Greenough, R., Peppard, J., Roy, R., Shehab, E., Braganza, A., Tiwari, A., Alcock, J., Angus, J., Bastl, M., Cousens, A., Irving, P., Johnson, M., Kingston, J., Lockett, H., Martinez, V., Michele, P., Tranfield, D., Walton, I. and Wilson, H. (2007) 'State-of-the-art in product service-systems', Proceedings of the Institution of Mechanical Engineers, Part B: Journal of Engineering Manufacture, Vol. 221, No. 10, pp. 15431552.

Borgo, S. and Leitão, P., 2007. 'Foundations for a core ontology of manufacturing'. In Ontologies, pp. 751-775, Springer US.

Borsato, M. (2014) 'Bridging the gap between product lifecycle management and sustainability in manufacturing through ontology building', Computers in Industry, Vol. 65, pp. 258-269. 
Bruno G., Korf R., Lentes J., Zimmerman N., (2016). "Efficient management of product lifecycle information through a semantic platform". Int. J. Product Lifecycle Management, Vol. 9, No. 1.

Cai, M., Zhang, W. Y. and Zhang, K. (2011) 'ManuHub: A Semantic Web System for Ontology-Based Service Management in Distributed Manufacturing Environments', IEEE Transactions On Systems, Man, And Cybernetics-Part A: Systems And Humans, Vol. 41, No. 3, pp 574 - 582

Chungoora, N., Gunendran, G.A., Young, R.I.M., Usman, Z., Anjum, N.A., Palmer, C., Harding, J.A., Case, K., and Cutting-Decelle, A.F. (2012) 'Extending product lifecycle management for manufacturing knowledge sharing', Proceedings of the Institution of Mechanical Engineers Part B - Journal of Engineering Manufacture, Vol. 226, pp. 2047-2063.

Cook M.B., Bhamra T.A., Lemon M. (2006) 'The transfer and application of Product Service Systems: from academia to UK manufacturing firms". Journal of Cleaner Production. Volume 14, Issue 17, 2006, Pages 1455-1465.

Falcon (2016). Available from: http://falcon-project.eu/ [Accessed July 2016].

Gaiardelli, P., Resta, B., Martinez, V., Pinto, R. and Albores, P. (2014) 'A classification model for product-service offerings', Journal of Cleaner Production, Vol. 6, pp.507-519.

Gebauer, H., Fleisch, E. and Friedli, T. (2005) 'Overcoming the service paradox in manufacturing companies', European Management Journal, Vol. 23, Iss. 1, pp. 14-26.

Goedkoop, M., van Halen, C., te Riele, H., and Rommens, P. (1999) 'Product Service-Systems, ecological and economic basics' Report for Dutch Ministries of Environment (VROM) and Economic Affairs (EZ).

Gruber, Thomas R. (1993). "A translation approach to portable ontology specifications". Knowledge Acquisition. 5 (2): 199-220. doi:10.1006/knac.1993.1008.

Hastilow, N. (2013) 'An Ontological Approach to Manufacturing Systems Interoperability in Dynamic Change Environments', Ph.D. School of Mechanical and Manufacturing Engineering, Loughborough University, UK. 
A reference ontology approach to support product-service production

Highfleet Ontology Library Reference, 2014. Baltimore, MA: HIGHFLEET Inc.

Imran, M. (2013) 'Towards an Assembly Reference Ontology for Assembly Knowledge Sharing', Ph.D. School of Mechanical and Manufacturing Engineering, Loughborough University, UK.

International Organization for Standardization (2007) 'ISO/IEC 24707, Information technology - Common Logic (CL): a framework for a family of logic-based languages', Genève: ISO.

IEC 62264 (2002) 'Enterprise-Control System Integration, Part 1. Models and Terminology, Part 2: Model Object Attributes', ISO/IEC, Geneva.

Kulvatunyou, B., Ivezic, N. and Lee, Y. (2014) 'On enhancing communication of the manufacturing service capability information using reference ontology', International Journal of Computer Integrated Manufacturing, Vol. 27, No. 12, pp. 1105-1135

Lee , J., Chae, H., Kim, C. and Kim, K. (2009) 'Design of product ontology architecture for collaborative enterprises', Expert Systems with Applications, Vol 36, pp. 2300-2309

Lee, J.H., Fenves, S.J., Bock, C., Suh, H-W., Sudarsan, R., Fiorentini, X., Sriram, R. (2012) "A Semantic Product Modeling Framework and its Application for Behavior Evaluation". IEEE Transactions on Automation Science and Engineering. Vol 9. No. 1.

Leitão, P., Colombo, A. and Restivo, F., 2005, ADACOR, A Collaborative Production Automation and Control Architecture, IEEE Intelligent Systems, Vol 20, Part 1, pp.58-66.

Li, M-S., Cabral, R., Doumeingts, G. and Popplewell, K., "Enterprise Interoperability: A concerted research roadmap for shaping business networking in the knowledge-based economy", published by the Commission for the European Communities, 2006, 45 pp, ISBN 92-79-02437-X.

LinkedDesign (2014 a)D4.3 Revised knowledge exploitation framework Available from http://www.linkeddesign.eu/deliverables/M30/LinkedDesign_Delive rable_4.3.pdf [accessed July 2016]

LinkedDesign (2014b) D3.3 The LinkedDesign Ontology Available from http://www.linkeddesign.eu/deliverables/M30/LinkedDesign_Delive rable_3.3.pdf [accessed July 2016]

Milicic, A., Perdikakis, A., El Kadiri, S., Kiritsis, D., Terzi, S., Paolo Fiordi, P., and Sadocco, S., 'Specialization of a Fundamental 
Ontology for Manufacturing Product Lifecycle Applications: A Case Study for Lifecycle Cost Assessment', Lecture Notes in Computer Science, Vol 7567, pp. 69-72.

MSEE Manufacturing Service Ecosystem. Available from http://www.msee-ip.eu/. [Accessed June 2015].

Muto, K., Kimita, K. and Shimomura, Y. (2015) 'A Guideline for ProductService-Systems Design Process', Proceedings of the 7th CIRP Conference on Industrial Product-Service Systems, Mines, St. Etienne, France, pp. 60-65.

Palmer, C., Urwin, E.N., Pinazo-Sánchez, J-M, Cid, F.S., Rodríguez, E.P., Pajkovska-Goceva, S. and Young, R.I.M. (2016) 'Reference Ontologies to Support the Development of Global Production Network Systems', Computers In Industry, Vol. 77, pp. 48-60.

Panetto, H., Dassisti, M., and Tursi, A. (2012) 'ONTO-PDM: Productdriven ONTOlogy for Product Data Management interoperability within manufacturing process environment', Advanced Engineering Informatics, Vol. 26, pp. 334-348

Peruzzini, M., Marilungo, E., Germani, M. (2014) 'Sustainable ProductService Design in manufacturing industry', Proceedings of $13^{\text {th }}$ International Design Conference, Dubrovnik, Croatia, pp. 995-964.

Spring, M., and Araujo, L. (2013) 'Beyond the service factory: Service innovation in manufacturing supply networks', Industrial Marketing Management, Vol. 42, pp. 59-70.

Usman, Z., Young, R.I.M., Chungoora, N., Case, K., Palmer, C. and Harding J.A. (2013) 'Towards a formal manufacturing reference ontology', International Journal of Production Research, Vol. 51, No. 22, pp. 6553-6572.

Vandermerwe, S. and Rada, J. (1988) 'Servitization of business: adding value by adding services', European Management Journal, Vol. 6, no. 4 , pp. $314-324$.

Vezzoli, C., Ceschin, F., Diehl, J.C. and Kohtala, C. (2015), 'New design challenges to widely implement Sustainable Product-Service Systems', Journal of Cleaner Production, Vol. 97, pp. 1-12.

Wang, P.P., Ming, X.G., Wu, Z.Y., Zheng, M.K., and Xu Z.T. (2014) 'Research on industrial product-service configuration driven by value demands based on ontology modeling', Computers in Industry, Vol. 65, pp. 247-257.

Weichhart, G., Molina, A., Chen, D., Whitman, L.E. and Vernadat, F., 2016. 'Challenges and current developments for sensing, smart and sustainable enterprise systems', Computers in Industry, vol 79, pp.34-46. 
A reference ontology approach to support product-service production

Young R I M., Gunendran A G., Chungoora N., Harding J A., Case K. (2009) "Enabling interoperable manufacturing knowledge sharing in PLM". In: Proceedings of the 6th international conference on product lifecycle management, University of Bath, Bath, UK.

Zelm, M. and Chen, D. (2015) 'Standardisation Developments for Enterprise Interoperability and the Manufacturing Service Domain', in Enterprise Interoperability part8 (eds M. Lauras, M. Zelm, B. Archimède, F. Bénaben and G. Doumeingts), John Wiley \& Sons, Inc., Hoboken, NJ, USA. 